\title{
The Review of User Experience and User Interface Design of Hospital Information System to Improve Health Care Service
}

\author{
Rully Sumarlin \\ Master of Design \\ Universitas Komputer Indonesia \\ Bandung, Indonesia \\ rully.sumarlin@email.unikom.ac.id
}

\begin{abstract}
The research aimed to maximize Hospital Information System is a software application that facilitates hospital management staff and doctors to improve their healthcare service quality. In Indonesia, initially this application is used mainly as a billing system in the hospital, which the outputs are hospital operational costs, patient treatment cost and pharmacy purchasing. As explained before, HIS now developing from billing system only, into a wider and best management system in the whole operating hospital services. The development of HIS eventually will lead in demands for a nicest design, whether it is an optimal technology design or a finest visual design. These two can help the user to maximize the benefits of the that can result in improvement of patient service in general and more valued by design can be reached. This is an interesting phenomenon to research. The interface design has an important role to provide a better Hospital Information System to fulfill user's needs.
\end{abstract}

Keywords-User Interface Design, User Experience, Health Information System

\section{INTRODUCTION}

Hospital Information System is a software application that facilitates hospital's management staff and doctors to improve their healthcare service quality. In Indonesia, initially this application is used mainly as a billing system in hospital, which the output are hospital's operational costs, patient's treatment cost and pharmacy's purchasing [1].

Nowadays, Hospital Information System is developing and transforming as a comprehensive and integrated system that can be used to manage administrative, financial and clinical aspect of a hospital, such as managing electronic medical records storage system, pharmacy's management system, accounting system, nursing care system, etc.
According to M.L. Wong, C.W. Khong, H. Thwaites (2012), Interface designers play an important role in the design process where they practice human factors (HF) to ensure the design of the product simplifies life for everyone, the interaction between product and user is improved, to enhance the usability, and making sure that the product benefit people of all ages and abilities. Designers can study the human posture and consider some level of human anatomy when they are manipulating their designs through sketches, and to ascertain how the user interacts with the design. This method is important in the ideation stage, where it helps designers to quickly explore ideas via sketching. Sketches of screen-based annotations showing user interaction with proposed graphical user interfaces (GUI) are generated in the process [2].

This developing phenomenon is a result of users' demands to have a better experience in Hospital Information System that easy to use, more beneficial and can give the best support for faster and better health service [3]. The interface design has an important part in this technology, where the designers can create a technology that fulfill user's needs. According to Shneiderman (2010) Organizing the display must have important consistency of data display, efficient information assimilation by the user, minimal memory load on the user, compatibility of data display with data entry, flexibility for user control of data display [4].

According to Joedawinata, Ahadiat (2017) the importance of design in technology as emphasized by William Henry Mayall [5], the development of Hospital Information System eventually will lead in demands for a better design, whether it is a better technology design or a better visual design. These two can help the user to maximize the benefits of the Hospital Information System that can 
result in improvement of patient service in general and more valued by design can be reached [6]. Our role as a designer that we are part of the change process that can initiate change in hospital information system that created [7]. According to Miller, Robert H., and Ida Sim (2004) identified a consistent relationship be- tween greater electronic documentation by physicians and greater quality improvident and financial benefits. Just as computerized physician order entry (CPOE) appears central to generating benefits in hospital settings, physician electronic documentation appears central to generating benefits in ambulatory care settings [8].

The purpose of this study is to describe the change process Hospital Information System interface design in Dewi Sri Hospital since 1997 until now, based on their needs to improve hospital service quality, as explained by Ahadiat in Teori Fenomena Perubahan (The Change Phenomenon Theory). Ahadiat [9] This theory explain that in change phenomenon there are things that changed, things that remain the same, things that new and things that missing.

\section{METHOD}

This study took place in Dewi Sri Hospital Karawang that built in 1997 as one of the oldest hospital in Karawang.

With many patients that need health care in Karawang, Dewi Sri need to always improve their service in every aspects.

The method of study is using quality research method based on interview with users about Hospital Information System and observation of its implementation and how they affect Dewi Sri Hospital Karawang Health Service in general.

\section{RESULTS AND DISCUSSION}

Based on interview and observation, Dewi Sri Hospital Karawang created their own system that help in billing and accounting in 2002. This system was desktop based and need to be installed first in computer. At first the system can accommodate their needs in managing financial aspect of the hospital [10].

Through the years, with the increasing of patients flow in Dewi Sri Hospital Karawang, their service become slower. Paper medical record need a lot of space, difficult to manage and workflow efficiency disrupt [11]. Clinical service by Nurse, General Practioner Doctor or Specialists Doctor, Pharmacist getting more complex and dynamic and need better support system. They realize that they need better and faster technology that can be used to keep improving their health service[12].

Fortunately, the Web 2.0 era has brought many capabilities into a web-based application environment. This era also brought a big swift in technology for Hospital Information System [13]. Majority of Hospital Information System vendor are changing their technology into a webbased system.
One of many benefits from web-based application is less hassle in managing the client side system. We do not have to install it on client side because we can access the system easily from a server by web browser (web based) [9]. This change impact in faster patient's health service due to time efficiency [14].

From visual design, the old visual design is usually plain and boring because the function is related with billing system only [15]. Now as the function expanding and become more complex, the visual design needed to become more attractive and user friendly or easily throughout various Operating System such as windows based system, android, ios, linux, etc. The interface design of HIS has to be user friendly and easy to use, as easy as we operate common social media applications such as Facebook, Instagram, Twitter that are already familiar to most users.

The change process of Hospital Information System in Dewi Sri Hospital Karawang.

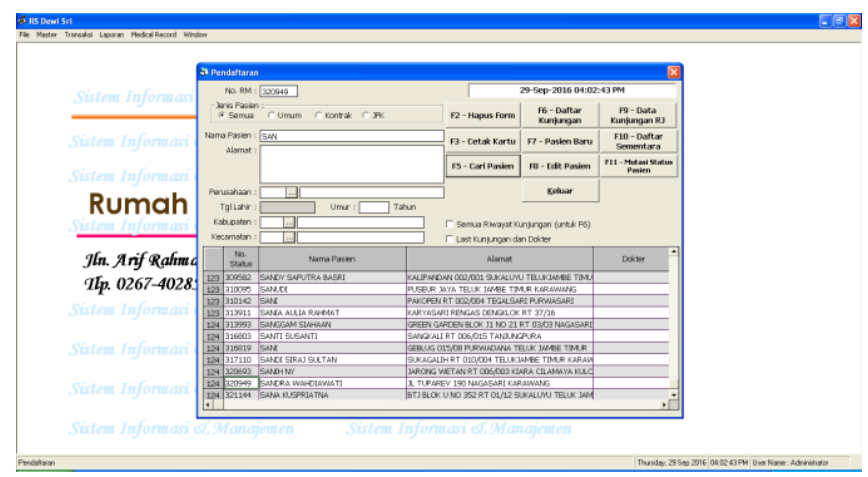

Fig 1. Patients Registration

The picture shows the patients registration system used in Dewi Sri Hospital Karawang in 2016 which still using desktop based application.

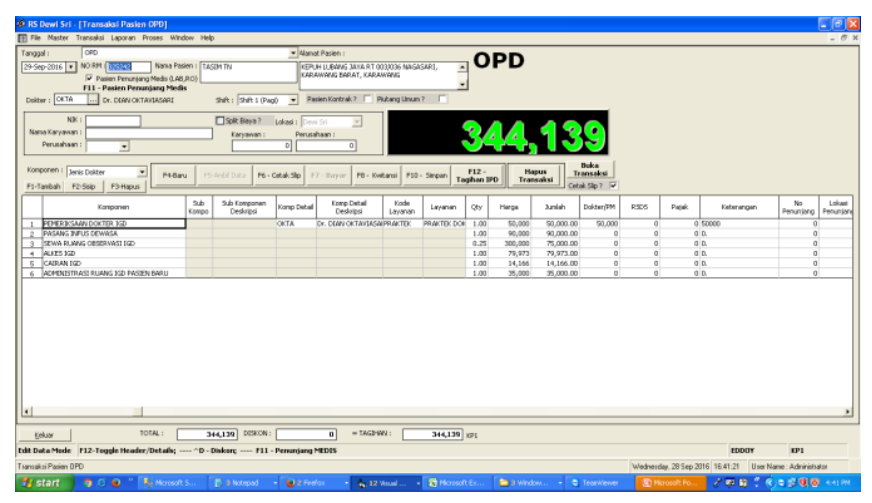

Fig 2. Billing System 


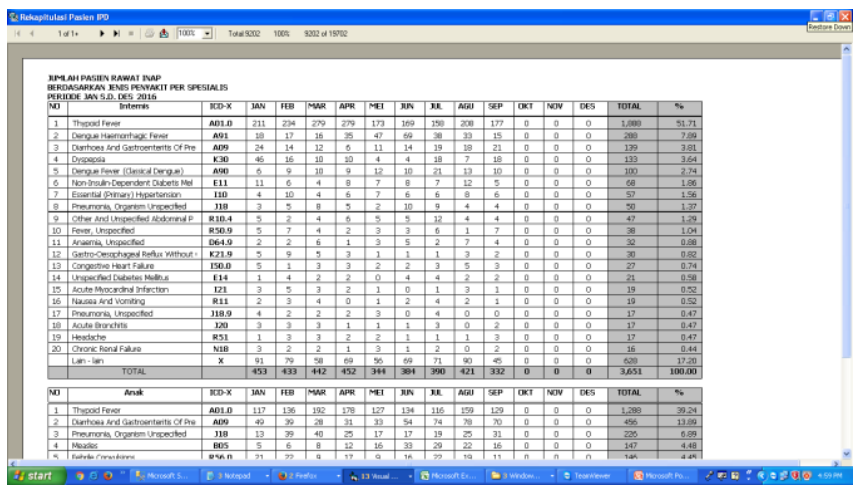

Fig 3. Patients Report

As explained before, simple and desktop based application of Hospital Information System in Dewi Sri Hospital Karawang is no longer suitable. The system cannot accommodate the complexity of health service they provide, the interface design is plain and boring, the design has rigid form and less interactive.

This is where designer play important role to create interface design that simplifies Dewi Sri hospital Karawang health Service, improved interaction between products, improved user experience, enhance usability and benefit in providing good health service for patients.

The latest web-based Hospital Information System in Dewi Sri Hospital Karawang has a better interface design for a better user experience. Dewi Sri are now using ZiCare Hospital Information System.

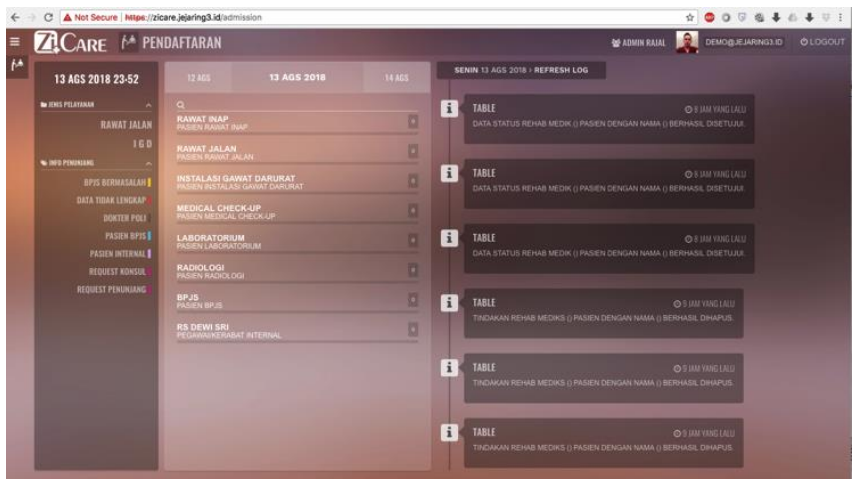

Fig 4. Patients registration

The latest patient registration system used in Dewi Sri Hospital Karawang. The interface design is more interactive. It linked to many other item needed in their health service.

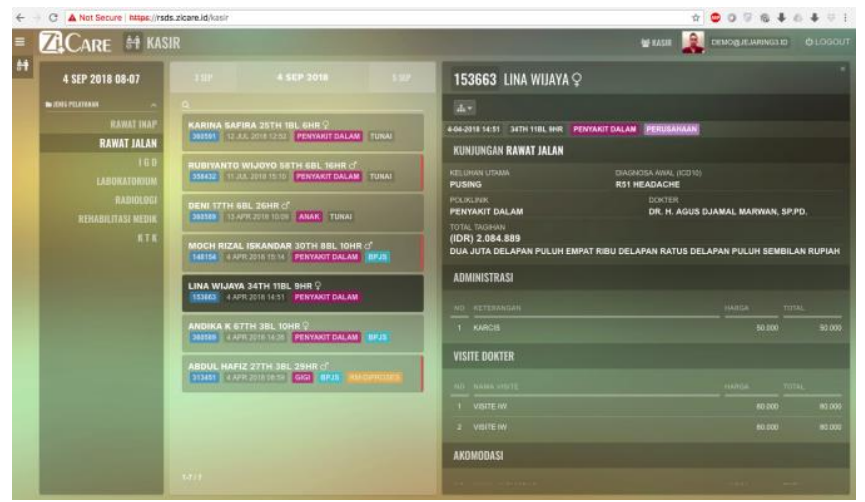

Fig 5. Admission \& Billing System

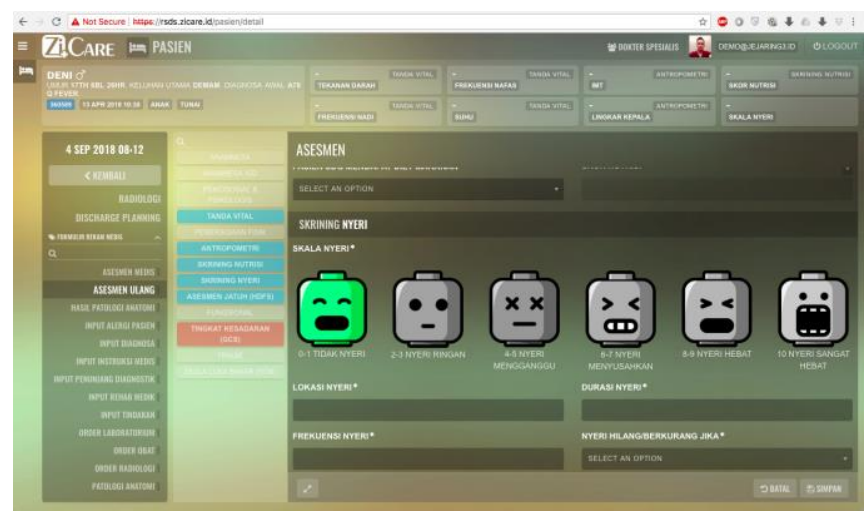

Fig 6. Patients status assessment

This picture shows more detailed patient's summary starting from their name, age, address, medical condition in general, who treat them and also payment system.

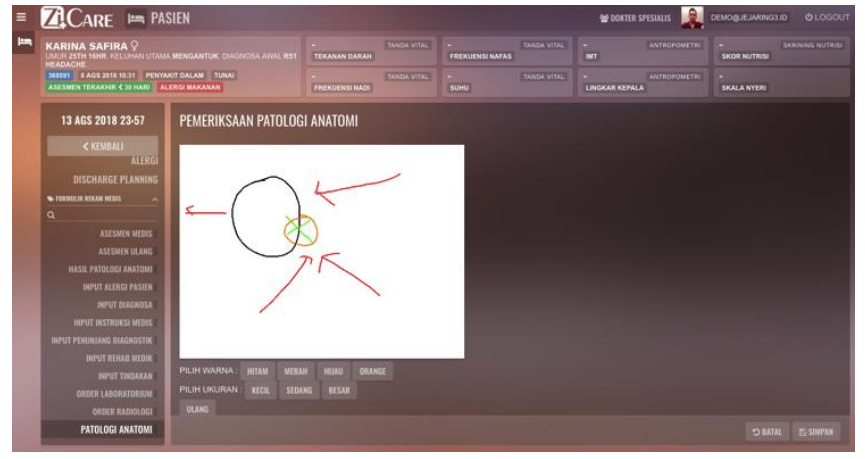

Fig 7. Medical Support with canvas model 


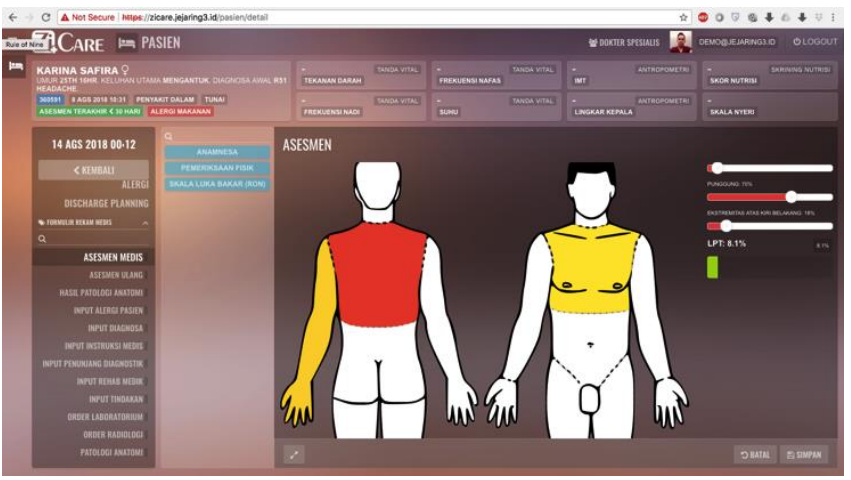

Fig 8. Patient chart as part of e-medical record

\section{CONCLUSION}

There are two big factors that leading the developing and change process of Hospital Information Sytem, those are the development of technology and user's needs to accomodate their dynamic and complex service based on their experience before. New interface design that canbe created to accomodate these needs so the improvement of service can be reached.

\section{ACKNOWLEDGMENT}

Author thank Allah Swt, Dewi Sri Hospital Karawang for this research, PT Jejaring Tiga Artha for giving knowledge about Zi.Care Hospital Information System Application, my family, wife drg Tutun Rendrawulan, Dr.Ir.H.Abdusy Syakur Amin,M.Eng, Garut University.

\section{REFERENCES}

[1] Dhyana Sharon Ross and R. Venkatesh, "Role of Information System in Improving Healthcare quality in Hopitals. VIT Buisness Scholl Chennai, VIT University, Chennai - 600127 July 2016.
[2] M.L. Wong, C.W. Khong, H. Thwaites Applied UX and UCD Design Process in Interface Design, Faculty of Creative Multimedia, Multimedia University, 63100 Cyberjaya, Malaysia, 2012.

[3] Aniza Ismail, Ahmad Taufik Jamil, Ahmad Fareed A rahman, Jannatul Madihah Abu Bakar, Natrah Modh Saad, Hussain Saadi, "The Implementation of Hostpital Information System (HIS) In Tertiary Hospital in Malaysia: A Qualitative Strudy," Malaysian Journal of Public Health Medicine 2010, Vol. 10(2):16-24

[4] Jonatahn Andreson, John McRee, Robb Wislon \& The Effective UI Team, "Effective UI," Publish by O'Really Media, Inc., 1005 Gravenstein Higway North, Sebastopol CA 95472. 2010

[5] Joedawinata, Ahadiat. Applied Aesthetic Desertation Theory 9 Points. Applied Aesthetic Lecture Materials. Bandung. 2017

[6] Dhyana Sharon Ross and R. Venkatesh. "Role of Information System in Improving Healthcare quality in Hopitals. VIT Buisness Scholl Chennai, VIT University, Chennai - 600127. 2016.

[7] M.L. Wong, C.W. Khong, H. Thwaites. Applied UX and UCD Design Process in Interface Design, Faculty of Creative Multimedia, Multimedia University, 63100 Cyberjaya, Malaysia. 2012.

[8] Bohm, David. On Creativity, London and New York: Routledge.

[9] Supriyono, Rahmat. 2010. DESAIN KOMUNIKASI VISUAL- Teori dan Aplikasi. Yogyakarta: Andi Offset. 2006.

[10] Aniza Ismail, Ahmad Taufik Jamil, Ahmad Fareed A rahman, Jannatul Madihah Abu Bakar,Natrah Modh Saad, Hussain Saadi, "The Implementation of Hostpital Information System (HIS) In Tertiary Hospital in Malaysia: A Qualitative Study," Malaysian Journal of Public Health Medicine Vol. 10(2):16-24. 2010.

[11] Ludwick, Dave A., and John Doucette. "Adopting electronic medical records in primary care: lessons learned from health information systems implementation experience in seven countries." International journal of medical informatics 78.1 (2009): 22-31.

[12] Ash, Joan S., Marc Berg, and Enrico Coiera. "Some unintended consequences of information technology in health care: the nature of patient care information system-related errors." Journal of the American Medical Informatics Association 11.2 (2004): 104-112.

[13] Miller, Robert H., and Ida Sim. "Physicians' use of electronic medical records: barriers and solutions." Health affairs 23.2 (2004): 116-126.

[14] Shneiderman, Ben. Designing the user interface: strategies for effective human-computer interaction. Pearson Education India, 2010.

[15] Pai, Fan-Yun, and Kai-I. Huang. "Applying the technology acceptance model to the introduction of healthcare information systems." Technological Forecasting and Social Change 78.4 (2011): 650-660. 